DOI:

УДК 669.013.002.5:531.3

О.0. Бейгул, д-р техн. наук, професор, dstu.mo@i.ua

Д.І. Грищенко, аспірант, dstu.mo@i.ua

В.о. Бейгул, канд. техн. наук, доцент, dstu.mo@i.ua

Г.Л. Лепетова, канд. техн. наук, доцент, dstu.mo@i.ua

Дніпровський державний технічний університет

\title{
ВПЛИВ ТИПУ ПІДВІСКИ ПРИ ФОРМУВАННІ ДИНАМІЧНИХ НАВАНТАЖЕНЬ НА НЕСУЧУ СИСТЕМУ ЗЧЛЕНОВАНОГО КОНТЕЙНЕРОВОЗА 3 БУГЕЛЬНОЮ РАМОЮ
}

У роботі розроблена математична модель збуреного руху зчленованого контейнеровоза з бугельною рамою на пневмоколісному ході методами аналітичної механіки з залученням рівняння Лагранжа другого роду. Визначені власні динамічні характеристики системи, критичні швидкості руху, отримані коефіиієнти динамічності в дорезонансній та зарезонансній зонах для жорсткої та пружної підвісок, що забезпечує точне визначення розрахункових зусиль, раціональну металомісткість конструкиій.

Ключові слова: динамічне навантаження; зчленований контейнеровоз; математична модель; бугельна рама; аналітична механіка.

Mathematical model of disturbance motion for articulated container truck on pneumatic wheels has been worked out by analytical mechanics method with Lagrange equation of second type. Natural dynamical characteristic, critical speed of motion, dynamic coefficient have been received for rigid and elastic suspensions, that has been secured accurace of force calculation, rational metalcapacity of constructions.

Keywords: articulated dynamical loads; articulated container truck; mathematical model; band loop frame; analytical mechanics.

\section{Постановка проблеми}

Залучення контейнеровозів на пневмоколісному ході, у тому числі з бугельною несучою системою, до транспортних операцій у технологічних лініях металургійного виробництва має пріоритетне значення. Контейнерна доставка дозволяє знизити собівартість вантажних операцій, підвищити продуктивність праці, забезпечити умови для комплексної механізації та автоматизації транспортних операцій, знизити затрати на зовнішню тару та пакування вантажів, підвищити пропускну здатність навантажувально-розвантажувальних пунктів, збільшити ступінь використання складських приміщень.

Контейнерні перевезення дозволяють автоматизувати вантажні, складські операції, скоротити їх кількість, підвищити продуктивність праці у порівнянні з іншими способами перевезень, прискорити вантажні операції, підвищити пропускну здатність місць завантаження та розвантаження, збільшити ступінь використання складських приміщень.

По своєму призначенню контейнери підрозділяються на універсальні та спеціалізовані. Універсальні контейнери призначені для перевезення тарно-штучних вантажів широкої номенклатури, спеціалізовані контейнери призначені для транспортування обмеженої номенклатури чи окремих видів вантажів.

Розвиток контейнерних перевезень спричиняє появу нових компоновок підйомнотранспортних машин. Так, для виконання операцій, пов'язаних з автономним навантаженням, транспортуванням, розвантаженням та складуванням контейнерів, пакетованих вантажів на піддонах ефективними вважаються технологічні контейнеровози на пневмоколісному ході 3 бугельною рамою, які не мають аналогів як у вітчизняному, так і в зарубіжному автомобілебудуванні.

Аналіз останніх досліджень та публікацій

Контейнеровози з бугельною несучою системою відомі трьох типів [1-4]:

а) спецавтотранспортні засоби з бугельною рамою; 
б) одновісні тягачі з бугельними напівпричепами;

в) зчленовані контейнеровози з бугельною рамою.

Спецавтотранспортний засіб - контейнеровоз з бугельною рамою має комбіновану несучу систему, поєднуючи відкритий та закритий типи профілів силових елементів. У передній частині, де рама драбинного типу з силовими елементами відкритого профілю, міститься двигун, привод, підвіска, кабіна водія, у задній частині два силових елементи відкритої несучої системи у вигляді підсилених лонжеронів закритого профілю з консольним кріпленням підвіски, що складає сутність бугельної рами. Контейнер міститься між лонжеронами на ложементах 3 гідроприводом [1].

Основу другого типу контейнеровозів складають одновісні тягачі, за допомогою яких можна переміщувати на спеціальних візках з бугельною рамою контейнери, піддони 3 різним вантажем. Тягач має шарнірне з'єднання з бугельною рамою, завдяки якому машина має малий радіус повороту. Передні ведучі колеса та шарнірне зчеплення дозволяють низько розташовувати центр маси як цієї машини, так і вантажу, який перевозиться, що підвищує стійкість такої системи [3].

Зчленований контейнеровоз з бугельною несучою системою складається 3 двоосного тягача та одновісного напівпричепа з бугельною рамою $[5,6]$. Лонжерони напівпричепа мають закритий профіль, що надає можливість консольного кріплення елементів підвіски, адже закритий профіль лонжеронів сприймає крутильні моменти. Контейнер міститься між лонжеронами бугельної рами на чотирьох лонжеронах з гідро-, пнемо- чи механічним приводами для завантаження, транспортування чи розвантаження. Вісь напівпричепа міститься в його центральній частині, тим самим вузол зчеплення тягача 3 напівпричепом істотно розвантажується. Третій тип контейнеровозів з бугельною рамою слід вважати найбільш універсальним.

\section{Формування мети дослідження}

3 наведеного вище аналізу витікає, що нетрадиційна бугельна компоновка несучих систем контейнеровозів спричиняє відсутність досвіду їх розробки, виготовлення, експлуатації. Існуючі підходи при проектуванні несучих систем традиційного спецавтотранспорту не враховують формування навантажень, сприйняття та передачу внутрішніх зусиль у силових елементах бугельних несучих систем. Відомі математичні моделі збуреного руху технологічного спецавтотранспорту не враховують компонувальних особливостей зчленованих контейнеровозів 3 бугельною несучою системою. У науковій літературі практично відсутні матеріали, присвячені дослідженню та розробці металургійних контейнеровозів з бугельною несучою системою при очевидній актуальності таких машин у технологічних лініях металургійних підприємств.

Таким чином, можна сформулювати наступну мету дослідження: виявити вплив типу підвіски зчленованого контейнеровоза на пневмоколісному ході з бугельною рамою на формування динамічних навантажень на силові елементи несучої системи у збуреному русі по технологічних дорогах.

\section{Виклад основного матеріалу}

Бугельна компоновка несучих систем технологічних транспортних засобів досить нетрадиційна. Як свідчить огляд літературних джерел, лише поодинокі наукові праці присвячені таким машинам. Якщо для звичайної компоновки, особливо у загальному автомобілебудуванні, накопичений багатий досвід розробки математичних моделей збуреного руху, формування зовнішніх навантажень, внутрішніх зусиль, то для зчленованих контейнеровозів на пневмоколісному ході з бугельною рамою все доводиться робити вперше.

Зчленований контейнеровоз утворює дволанкову динамічну систему з високо розташованим центром маси у ланці, де міститься контейнер (рис. 1). I саме ця обставина спричиняє постановку ряду задач збуреного руху у поздовжній площині [6-10].

Диференціальні рівняння збуреного руху отримуємо у формі рівняння Лагранжа другого роду [11]:

$$
\frac{d}{d t}\left(\frac{\partial T}{\partial \dot{q}_{j}}\right)-\frac{\partial T}{\partial q_{j}}=-\frac{\partial \Pi}{\partial q_{j}}+Q_{j}^{F}, \quad j=1, \ldots, \ldots . . .,
$$


де $T$ - кінетична енергія системи, Дж; $\Pi$ - потенціальна енергія системи, Дж; $Q_{j}^{F}-j$-а узагальнена сила неконсервативного походження, Н (Н·м); $q_{j}-j$-а узагальнена координата; $S$ - кількість ступенів свободи системи.

Схема зчленованого контейнеровоза з жорсткою підвіскою подана на рис.1.

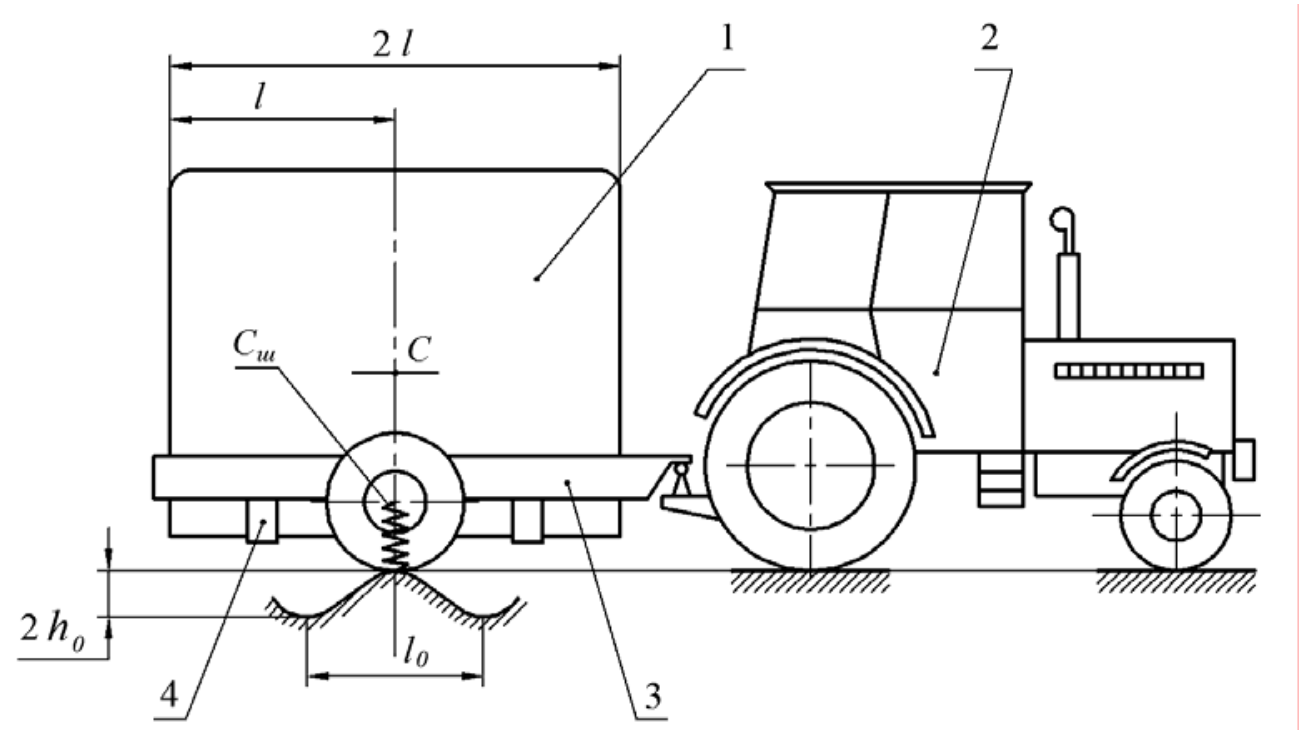

Puc. 1. Схема зчленованого контейнеровоза з жорсткою підвіскою: 1 - контейнер; 2 тягач; 3 - напівпричіп з бугельною рамою; 4 - ложемент

У якості важливого конструктивного припущення приймаємо, що передні та задні ложементи кріплення контейнера розташовані на однакових відстанях від осі напівпричепа.

У такому разі вузол з'єднання розвантажується, що дає підставу знехтувати вертикальним переміщенням точки кріплення напівпричепа до тягача у динамічній розрахунковій схемі зчленованого контейнеровоза. Диференціальне рівняння коливань у збуреному русі отримуємо у формі рівняння Лагранжа другого роду (1). Відповідно розрахунковій схемі система має один ступінь свободи, у якості узагальненої координати виступає кут повороту напівпричепа відносно поперечної осі, яка проходить через точку кріплення до тягача.

Кінетична енергія системи приймає наступний вигляд:

$$
T=\frac{1}{2} \dot{I} \dot{\varphi}^{2}+\frac{1}{2} m v^{2},
$$

де $T$ - кінетична енергія системи, Дж; $I$ - момент інерції напівпричепа 3 контейнером відносно поперечної осі, яка проходить через опорну точку, кг м $^{2} ; \dot{\varphi}-$ кутова швидкість напівпричепа у коливаннях, $\mathrm{c} ; m-$ маса напівпричепа 3 контейнером, кг; $v$ швидкість руху контейнеровоза, м/с.

Потенціальна енергія системи приймає наступний вигляд:

$$
\Pi=\frac{1}{2} \cdot 2 C_{\mathrm{\amalg}}(l \varphi-h)^{2}=C_{\mathrm{\amalg}}(l \varphi-h)^{2},
$$

де $\Pi$ - потенціальна енергія системи, Дж; $C_{\text {ш }}$ - радіальна жорсткість пневматики підвіски, $\mathrm{H} / \mathrm{m} ; l-$ відстань від точки зчеплення до центру маси напівпричепа з контейнером, м; $\varphi-$ кут повороту напівпричепа у поздовжній площині, рад; $h$ - поточна висота нерівностей технологічної дороги, м.

Виконуємо диференціювання за схемою рівняння Лагранжа другого роду: 


$$
\begin{gathered}
\frac{\partial T}{\partial \dot{\varphi}}=\frac{1}{2} I \cdot 2 \dot{\varphi}=I \dot{\varphi} ; \quad \frac{d}{d t}\left(\frac{\partial T}{\partial \dot{\varphi}}\right)=I \ddot{\varphi} ; \quad \frac{\partial T}{\partial \varphi} \equiv 0 ; \\
\frac{\partial \Pi}{\partial \varphi}=C_{\mathrm{\amalg}} \cdot 2(l \varphi-h) l=2 C_{\mathrm{\amalg}} l^{2} \varphi-2 C_{\mathrm{\amalg}} l h .
\end{gathered}
$$

Об’єднуючи ці вирази, нехтуючи силами неконсервативного походження, отримуємо диференціальне рівняння збуреного руху зчленованого контейнеровоза $з$ жорсткою підвіскою:

$$
I \ddot{\varphi}+2 C_{\mathrm{W}} l^{2} \varphi-2 C_{\mathrm{W}} l h=0 .
$$

Останній доданок у рівнянні (2.4) переносимо у праву частину:

$$
I \ddot{\varphi}+2 C_{\mathrm{W}} l^{2} \varphi=2 C_{\mathrm{W}} l h .
$$

Ділимо рівняння (5) на $I$, отримуємо

$$
\ddot{\varphi}+\frac{2 C_{\mathrm{W}} l^{2}}{I} \varphi=\frac{2 C_{\mathrm{W}} l h}{I} .
$$

Вводимо наступне позначення:

$$
\frac{2 C_{\mathrm{Wl}} l^{2}}{I}=p^{2}
$$

Переписуємо рівняння (6) з урахуванням (7):

$$
\ddot{\varphi}+p^{2} \varphi=\frac{2 C_{\mathrm{W}} l h}{I},
$$

де $p$ - кутова частина власних коливань напівпричепа 3 контейнером, 1/c.

У загальному вигляді можна записати

$$
h=h_{0} \sin \frac{2 \pi x}{l_{0}},
$$

де $h_{0}$ - амплітудне значення профілю нерівностей, м; $x$ - абсциса апроксимуючої функції, м; $l_{0}$ - довжина синусоїди, яка апроксимує функцію нерівностей, м.

При русі системи

$$
x=v t .
$$

3 урахуванням виразу (10) поточна висота нерівностей дорівнює

або після введення нового позначення

$$
h=h_{0} \sin \frac{2 \pi v}{l_{0}} t
$$

$$
h=h_{0} \sin \omega t,
$$

де $\omega-$ кругова частота кінематичних збурень, $1 / \mathrm{c}$.

$$
\omega=\frac{2 \pi v}{l_{0}} .
$$

Переписуємо рівняння (8) з урахуванням виразу (12):

$$
\ddot{\varphi}+p^{2} \varphi=\frac{2 C_{\mathrm{W}} l h_{0}}{I} \sin \omega t .
$$

Розв'язання рівняння (14) має наступний вигляд [12]:

$$
\varphi=C_{1} \cos p t+C_{2} \sin p t+\frac{2 C_{\mathrm{W}} l h_{0}}{I p^{2} \sqrt{\left(1-\frac{\omega^{2}}{p^{2}}\right)}} \sin (\omega t-\psi) .
$$

Перші два доданки у виразі (15) описують вільні коливання системи, які швидко затухають, третій додаток описує вимушені коливання з частотою кінематичних збурень. Таким чином, вимушені коливання описуються наступним рівнянням: 


$$
\varphi=\frac{2 C_{\amalg} l h_{0}}{I p^{2} \sqrt{\left(1-\frac{\omega^{2}}{p^{2}}\right)}} \sin (\omega t-\psi),
$$

де $\psi-$ фазовий кут вимушених коливань, рад.

Амплітуда вимушених коливань відповідно виразу (16) дорівнює

$$
\varphi_{0}=\frac{2 C_{\mathrm{W}} l h_{0}}{I p^{2} \sqrt{\left(1-\frac{\omega^{2}}{p^{2}}\right)^{2}}}
$$

або остаточно:

$$
\varphi_{0}= \pm \frac{2 C_{\mathrm{W}} l h_{0}}{I p^{2} \sqrt{\left(1-\frac{\omega^{2}}{p^{2}}\right)^{2}}} .
$$

У виразі (18) знак «+» приймається при $\left|\frac{\omega}{p}\right|<1$, знак «-» приймається при $\left|\frac{\omega}{p}\right|>1.3$ цього виразу безпосередньо витікає умова резонансу

$$
\omega=p \text {. }
$$

Після підстановки виразів кругових частот (13) та (7) в умову резонансу (19) отримуємо

$$
\frac{2 \pi v}{l_{0}}=\sqrt{\frac{2 C_{\amalg} l^{2}}{I}},
$$

звідки витікає критична швидкість контейнеровоза, при якій наступає резонанс:

$$
v_{k p}=\frac{l l_{0}}{2 \pi} \sqrt{\frac{2 C_{\amalg}}{I}} .
$$

Збільшення навантажень на вузли підвіски контейнеровоза, а разом з тим і на бугельну несучу систему напівпричепа при русі по нерівностях технологічних доріг будемо характеризувати коефіцієнтом динамічності, який залежить від конструктивних особливостей підвіски, параметрів шляху, швидкості руху і по суті виражається наступною залежністю:

$$
K_{\partial}=1+\frac{f_{\partial}}{f_{c}}
$$

де $K_{\partial}$ - коефіцієнт динамічності; $f_{\partial}$ - амплітуда коливань коліс напівпричепа у збуреному русі контейнеровоза, м; $f_{c}$ - статичний прогин пневматика жорсткої підвіски напівпричепа, м.

Розкриваємо амплітуду коливань коліс напівпричепа у збуреному русі контейнеровоза:

$$
f_{\partial}=\left(l \varphi_{0}-h_{0}\right) \sin \omega t .
$$

Записуємо вирази коефіцієнтів динамічності дорезонансній та зарезонансній зонах.

Дорезонансна зона:

$$
K_{\partial}^{(\partial)}=1+\frac{h_{0}}{f_{c}}\left[\frac{2 C_{m} l^{2}}{I_{p}^{2}\left(1-\frac{\omega^{2}}{p^{2}}\right)}-1\right]
$$

Зарезонансна зона: 


$$
K_{\partial}^{(3)}=1+\frac{h_{0}}{f_{c}}\left[\frac{2 C_{u m} l^{2}}{I_{p}^{2}\left(\frac{\omega^{2}}{p^{2}}-1\right)}-1\right] .
$$

Вводимо нове позначення:

$$
\frac{\omega}{p}=\chi
$$

Тоді вирази (24) та (25) приймають наступний вигляд:

$$
\begin{aligned}
& K_{\partial}^{(\partial)}=1+\frac{h_{0}}{f_{c}}\left[\frac{2 C_{u} l^{2}}{I_{p}^{2}\left(1-\chi^{2}\right)^{-1}}\right] ; \\
& \left.K_{\partial}^{(3)}=1+\frac{h_{0}}{f_{c}}\left[\frac{2 C_{u} l^{2}}{I_{p}^{2}\left(\chi^{2}-1\right)}\right)^{-1}\right]
\end{aligned}
$$

Розкриваємо власну кругову частоту у виразах (27) та (28) і далі скорочуємо їх:

$$
\begin{aligned}
& K_{\partial}^{(\partial)}=1+\frac{h_{0}}{f_{c}}\left[\frac{1}{1-\chi^{2}}-1\right] ; \\
& K_{\partial}^{(3)}=1+\frac{h_{0}}{f_{c}}\left[\frac{1}{\chi^{2}-1}-1\right] .
\end{aligned}
$$

Після простих перетворень вирази (29) та (30) приймають вигляд розв'язуючих умов для відношень кругових частот $\chi$ у дорезонансній та зарезонансній зонах:

$$
\chi^{(\partial)}=\sqrt{\frac{\left(K_{\partial}^{(\partial)}-1\right) f_{c}}{\left(K_{\partial}^{(\partial)}-1\right) f_{c}+h_{0}}},
$$

де $\chi^{(\partial)}$ - відношення кругових частот (26) у дорезонансній зоні;

$$
\chi^{(3)}=\sqrt{\frac{\left(K_{\partial}^{(3)}-1\right) f_{c}+2 h_{0}}{\left(K_{\partial}^{(3)}-1\right) f_{c}+h_{0}}},
$$

де $\chi^{(3)}$ - відношення кругових частот (26) у зарезонансній зоні.

Далі вертаємось до виразу (26), розриваємо його:

$$
\chi^{(\partial)}=\frac{\omega^{(\partial)}}{p}=\frac{2 \pi v^{(\partial)}}{l_{0}}: \sqrt{\frac{2 C_{u} l^{2}}{I}}=\frac{2 \pi}{l l_{0}} \sqrt{\frac{I}{2 C_{u} l^{2}}} v^{(\partial)},
$$

де $\omega^{(\partial)}$ - кругова частота кінематичних збурень у дорезонансній зоні, $1 / \mathrm{c} ; v^{(\partial)}$ - швидкість руху контейнеровоза у дорезонансній зоні, м/с.

Прирівнюємо вирази (31) та (33), отримуємо рівняння відносно швидкості руху контейнеровоза у дорезонансній зоні, при якій коефіцієнт динамічності дорівнює $K_{\partial}^{(\partial)}$ :

$$
v^{(\partial)}=\frac{l l_{0}}{2 \pi} \sqrt{\frac{2 C_{u}}{I}} \sqrt{\frac{\left(K_{\partial}^{(\partial)}-1\right) f_{c}}{\left(K_{\partial}^{(\partial)}-1\right) f_{c}+h_{0}}} .
$$

Розкриваємо вираз (26) для зарезонансної зони: 


$$
\chi^{(3)}=\frac{\omega^{(3)}}{p}=\frac{2 \pi v^{(3)}}{l_{0}}: \sqrt{\frac{2 C_{u} l^{2}}{I}}=\frac{2 \pi}{l l_{0}} \sqrt{\frac{I}{2 C_{m} l^{2}}} v^{(3)},
$$

де $\omega^{(3)}$ - кругова частота кінематичних збурень у зарезонансній зоні, $1 / \mathrm{c} ; v^{(3)}-$ швидкість руху контейнеровоза у зарезонансній зоні, м/с.

Прирівнюємо вирази (32) та (35), отримуємо рівняння відносно швидкості руху контейнеровоза у зарезонансній зоні, при якій коефіцієнт динамічності дорівнює $K_{\partial}^{(3)}$ :

$$
v^{(3)}=\frac{l l_{0}}{2 \pi} \sqrt{\frac{2 C_{u}}{I}} \sqrt{\frac{\left(K_{\partial}^{(3)}-1\right) f_{c}+2 h_{0}}{\left(K_{\partial}^{(3)}-1\right) f_{c}+h_{0}}} .
$$

Схема зчленованого контейнеровоза з пружною підвіскою представлена на рис. 2.

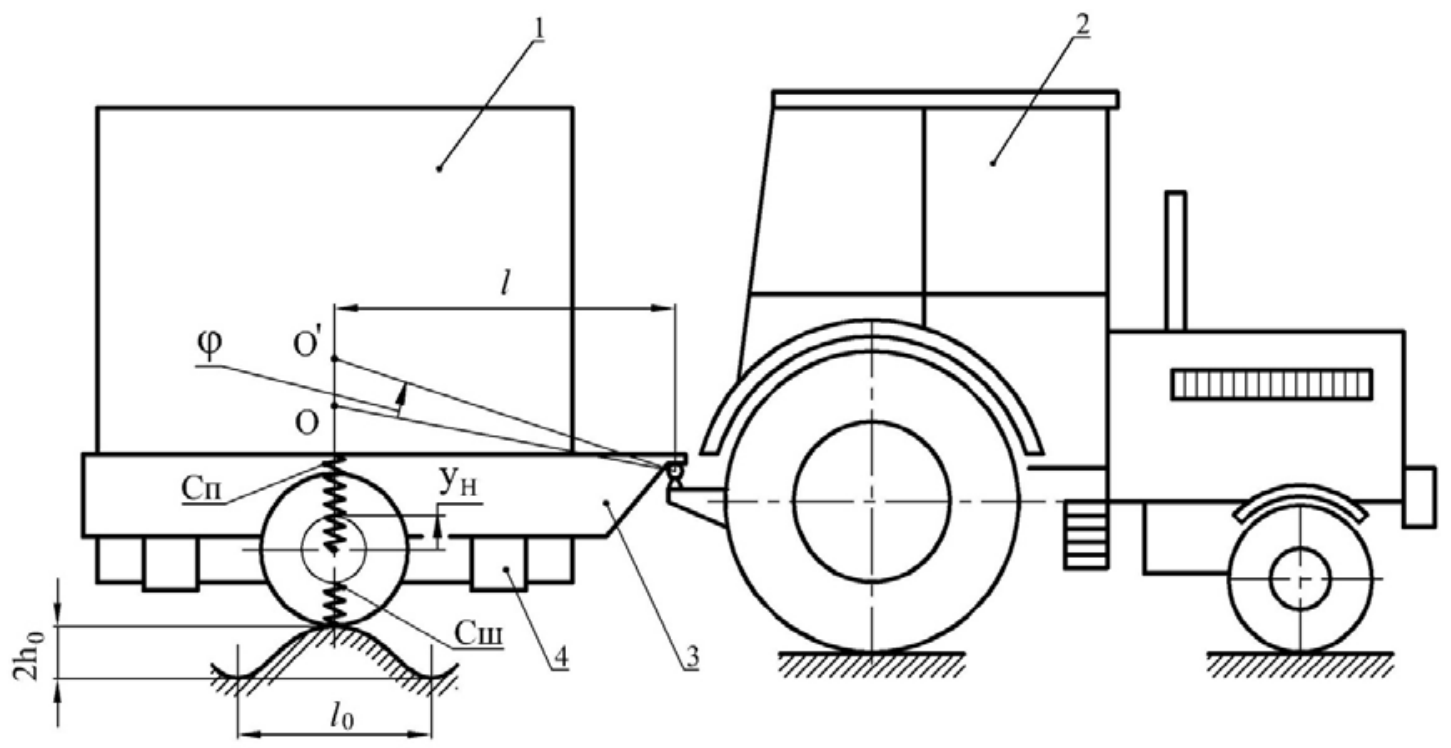

Puc. 2. Схема зчленованого контейнеровоза 3 пружною підвіскою: 1 - контейнер; $2-$ тягач; 3 - напівпричіп з бугельною рамою; 4 - ложемент

Диференціальні рівняння коливань у збуреному русі описуємо у формі рівняння Лагранжа другого роду (1). Відповідно розрахунковій схемі (рис. 2) приймаємо наступні узагальнені координати: $\varphi$ - кут повороту підресореної частини напівпричепа контейнеровоза відносно поперечній осі, яка проходить через точку з'єднання з тягачем; $y_{n}$ - переміщення непідресорених частин напівпричепа.

Кінематична енергія системи приймає наступний вигляд:

$$
T=\frac{1}{2}\left(m_{n}+2 m_{H}\right) v^{2}+\frac{1}{2} I_{n} \dot{\varphi}^{2}+\frac{1}{2} \cdot 2 m_{H} \dot{y}_{H}^{2},
$$

де $T$ - кінетична енергія системи, Дж; $m_{n}$ - маса підресореної частини напівпричепа 3 контейнером, кг; $m_{t}$ - маса половини непідресореної частини напівпричепа контейнеровоза, кг; $I_{n}$ момент інерції підресореної частини напівпричепа з контейнером відносно поперечної осі, яка проходить через точку зчеплення з тягачем, кг $\mathrm{M}^{2} ; v$ - швидкість руху контейнеровоза, м/с; $\dot{\varphi}$ — кутова швидкість напівпричепа у коливаннях збуреного руху у поздовжній площині, $\mathrm{c}^{-1}$; $\dot{y}_{н}$ - швидкість непідресорених частин напівпричепа у вертикальних коливаннях збуреного руху контейнеровоза, м/с.

Потенціальна енергія системи приймає наступний вигляд: 
або після скорочення:

$$
\Pi=\frac{1}{2} \cdot 2 C_{\Pi}\left(l \varphi-y_{H}\right)^{2}+\frac{1}{2} \cdot 2 C_{\mathrm{\amalg}}\left(y_{p}-h\right)^{2}
$$

$$
\Pi=C_{\Pi}\left(l \varphi-y_{H}\right)^{2}+C_{\mathrm{\amalg}}\left(y_{p}-h\right)^{2},
$$

де $\Pi$ - потенціальна енергія системи, Дж; $C_{\text {п }}$ - коефіцієнт жорсткості пружної підвіски напівпричепа, $\mathrm{H} / \mathrm{m} ; C_{u}$ - коефіцієнт радіальної жорсткості пневматика пружної підвіски напівпричепа, H/м; $h$ - висота профілю нерівностей технологічної дороги під підвіскою напівпричепа контейнеровоза, м.

Визначаємо диференціювання за схемою рівняння Лагранжа другого роду по першій узагальненій координаті:

$$
\begin{gathered}
\frac{\partial T}{\partial \dot{\varphi}}=\frac{1}{2} I_{n} \cdot 2 \dot{\varphi}=I_{n} \dot{\varphi} ; \quad \frac{d}{d t}\left(\frac{\partial T}{\partial \dot{\varphi}}\right)=I_{n} \ddot{\varphi} ; \quad \frac{\partial T}{\partial \varphi} \equiv 0 ; \\
\frac{\partial \Pi}{\partial \varphi}=C_{\Pi} \cdot 2\left(l \varphi-y_{H}\right) l=2 C_{\Pi} l^{2} \varphi-2 C_{\Pi} l y_{H} .
\end{gathered}
$$

Об'єднуючи ці вирази, нехтуючи силами неконсервативного походження, отримуємо перше диференціальне рівняння коливань у збуреному русі зчленованого контейнеровоза 3 пружною підвіскою.

$$
I \ddot{\varphi}+2 C_{\Pi} l^{2} \varphi-2 C_{\Pi} l y_{H}=0 .
$$

Виконуємо диференціювання за схемою Лагранжа другого роду по наступній узагальненій координаті:

$$
\begin{gathered}
\frac{\partial T}{\partial \dot{y}_{H}}=\frac{1}{2} \cdot 2 m_{H} \cdot 2 \dot{y}_{H}=2 m_{H} \dot{y}_{H} ; \quad \frac{d}{d t}\left(\frac{\partial T}{\partial \dot{y}_{H}}\right)=2 m_{H} \ddot{y} ; \quad \frac{\partial T}{\partial y_{H}} \equiv 0 ; \\
\frac{\partial \Pi}{\partial \varphi}=C_{\Pi} \cdot 2\left(l \varphi-y_{H}\right) \cdot(-1)+C_{\mathrm{\amalg}} \cdot 2\left(y_{H}-h\right) \cdot 1=-2 C_{\Pi} l \varphi+\left(C_{\Pi}+C_{\mathrm{\amalg}}\right) y_{H}-2 C_{\mathrm{\amalg}} h .
\end{gathered}
$$

Об'єднуючи ці вирази, нехтуючи силами неконсервативного походження, скорочуючи на «2», отримуємо друге диференціальне рівняння коливань у збуреному русі зчленованого контейнеровоза $з$ пружною підвіскою:

$$
m_{H} \ddot{y}_{H}=\left(C_{\Pi}+C_{\amalg}\right) y_{H}-C_{\Pi} l \varphi=C_{\amalg} h .
$$

Диференціальні рівняння (40) і (41) утворюють систему

$$
\left.\begin{array}{l}
I_{n} \ddot{\varphi}+2 C_{\Pi} l^{2} \varphi-C_{\Pi} l y_{H}=0 \\
-C_{\Pi} l \varphi+m_{H} \ddot{y}+\left(C_{\Pi}+C_{\amalg}\right) y_{H}=C_{\amalg} h .
\end{array}\right\}
$$

Підставляємо вираз (12) у систему рівнянь (42):

$$
\left.\begin{array}{l}
I_{n} \ddot{\varphi}+2 C_{\Pi} l^{2} \varphi-2 C_{\Pi} l y_{H}=0 \\
-C_{\Pi} l \varphi+m_{H} \ddot{y}+\left(C_{\Pi}+C_{\text {Ш }}\right) y_{H}=C_{\text {Ш }} h_{0} \sin \omega t .
\end{array}\right\}
$$

Розв'язання системи рівнянь (43) будемо розшукувати у вигляді

$$
\left.\begin{array}{l}
\varphi=A_{1} \sin \omega t \\
y_{H}=A_{2} \sin \omega t
\end{array}\right\}
$$

Підставляємо вираз (44) у систему рівнянь (43):

$$
\left.\begin{array}{l}
-I_{n} \omega^{2} A_{1} \sin \omega t+2 C_{\Pi} l^{2} A_{1} \sin \omega t-2 C_{\Pi} l A_{2} \sin \omega t=0 ; \\
-C_{\Pi} l A_{1} \sin \omega t-m_{H} \omega^{2} A_{2} \sin \omega t+\left(C_{\text {П }}+C_{\mathrm{\amalg}}\right) A_{2} \sin \omega t_{H}=C_{\mathrm{\amalg}} h_{0} \sin \omega t .
\end{array}\right\}
$$

Після скорочення отримуємо наступну систему алгебраїчних рівнянь відносно амплітуд коливань $A_{1}$ та $A_{2}$ : 


$$
\left.\begin{array}{l}
\left(2 C_{\Pi} l^{2}-I_{n} \omega^{2}\right) A_{1}-2 C_{\Pi} l A_{2}=0 ; \\
-C_{\Pi} l A_{1}+\left(C_{\Pi}+C_{\amalg}-m_{H} \omega^{2}\right) A_{2}=C_{\amalg} h_{0} .
\end{array}\right\}
$$

Розв'язуємо систему (46) способом Крамера [12]:

$$
A_{j}=\frac{\Delta_{j}}{D},
$$

де $A_{j}-j$-а амплітуда коливань; $D-$ головний визначник системи рівнянь; $\Delta_{j}-j$-й визначник, отриманий з головного визначника системи рівнянь шляхом заміни $j$-го стовпчика правими частинами системи (46).

Записуємо вище згадані визначники та розкриваємо їх:

$$
\begin{gathered}
D=\left|\begin{array}{cc}
2 C_{\Pi} l^{2}-I_{n} \omega^{2} & -2 C_{\Pi} l \\
C_{\Pi} l & C_{\Pi}+C_{\mathrm{\amalg}}-m_{H} \omega^{2}
\end{array}\right|= \\
=\left(2 C_{\Pi} l^{2}-I_{n} \omega^{2}\right)\left(C_{\Pi}+C_{\mathrm{\amalg}}-m_{H} \omega^{2}\right)-\left(C_{\Pi} l\right)\left(-2 C_{\Pi} l\right)= \\
=I_{n} m_{H}\left(\omega^{2}\right)^{2}-\left(I_{n} C_{\Pi}+I_{n} C_{\mathrm{\amalg}}+2 m_{H} l^{2} C_{\Pi}\right) \omega^{2}+2 C_{\Pi} C_{\amalg} l^{2} ; \\
\Delta_{1}=\left|\begin{array}{cc}
0 & -2 C_{\Pi} l \\
C_{\mathrm{\amalg}} h_{0} & C_{\Pi}+C_{\amalg}-m_{H} \omega^{2}
\end{array}\right|=2 C_{\Pi} C_{\amalg} l h_{0} ; \\
\Delta_{2}=\left|\begin{array}{cc}
2 C_{\Pi} l^{2}-I_{n} \omega^{2} & 0 \\
-C_{\Pi} h_{0} & C_{\mathrm{\amalg}} h_{0}
\end{array}\right|=\left(2 C_{\Pi} C_{\amalg} l^{2}-I_{n} C_{\amalg} \omega^{2}\right) h_{0} .
\end{gathered}
$$

Використовуючи визначення (48) - (50), записуємо вирази амплітуд коливань:

$$
\begin{aligned}
& A_{1}=\frac{2 C_{\Pi} C_{\mathrm{W}} l h_{0}}{I_{n} m_{H}\left(\omega^{2}\right)^{2}-\left[I_{n}\left(C_{\Pi}+C_{\mathrm{\amalg U}}\right)+2 m_{H} l^{2} C_{\Pi}\right] \omega^{2}+2 C_{\Pi} C_{\mathrm{U}} l^{2}} ; \\
& A_{1}=\frac{\left(2 C_{\Pi} C_{\mathrm{W}} l^{2}-I_{n} C_{\mathrm{W}} \omega^{2}\right) h_{0}}{I_{n} m_{H}\left(\omega^{2}\right)^{2}-\left[I_{n}\left(C_{\Pi}+C_{\mathrm{\amalg}}\right)+2 m_{H} l^{2} C_{\Pi}\right] \omega^{2}+2 C_{\Pi} C_{\mathrm{\amalg}} l^{2}} ;
\end{aligned}
$$

Як це витікає з виразів (51) та (52), при $h_{0}=0$, тобто при відсутності кінематичних збурень коливання системи не збуджуються, коли $A_{1}=0, A_{2}=0$.

3 іншого боку, при $h_{0} \neq 0$ амплітуда коливань по другій узагальненій координаті $A_{2}$ може дорівнювати нулю за наступної умови:

$$
2 C_{\Pi} C_{\mathrm{W}} l^{2}-I_{n} C_{\mathrm{W}} \omega^{2}=0
$$

або

$$
I_{n} C_{\mathrm{Ш}} \omega^{2}=2 C_{\Pi} C_{\mathrm{W}} l^{2}
$$

Звідки отримуємо розв'язуючу умову для кругової частоти кінематичних збурень $\omega$ :

$$
\omega=\sqrt{\frac{2 C_{\Pi} l^{2}}{I_{n}}} .
$$

Розкриваємо кругову частоту кінематичних збурень:

$$
\frac{2 \pi v}{l_{0}}=\sqrt{\frac{2 C_{\Pi} l^{2}}{I_{n}}},
$$

звідки отримуємо умову антирезонансу для другої узагальненої координати $y_{н}$ :

$$
v_{a p}=\frac{l l_{0}}{2 \pi} \sqrt{\frac{2 C_{\Pi}}{I_{n}}},
$$


де $v_{a p}$ - швидкість руху зчленованого контейнеровоза, при якій коливання по другій узагальненій координаті відсутні, м/с.

Якщо порівняти головний визначник (44) з відповідним частотним визначником вільних коливань системи «тягач-напівпричіп», то неважко збагнути, що вони в точності співпадають при $\omega=p$, де $p-$ власна кругова частота коливань системи. Але в цьому разі визначник обертається в нуль, оскільки саме за цієі умови мають бути найдені власні кругові частоти $p_{1}$ та $p_{2}$. При $D=0$, а $\Delta_{j} \neq 0$, як це витікає $з$ формули (43), амплітуди $A_{1}$ та $A_{2}$ безмежно зростають, що свідчить про появу резонансних режимів:

$$
I_{n} m_{H}\left(\omega^{2}\right)^{2}-\left[I_{n}\left(C_{\Pi}+C_{\text {ШШ }}\right)+2 m_{H} l^{2} C_{\Pi}\right] \omega^{2}+2 C_{\Pi} C_{\amalg} l^{2}=0 .
$$

Це біквадратне рівняння відносно $\omega$, воно має наступне розв'язання [12]:

$$
\begin{gathered}
\omega_{1,2}^{2}=\frac{\left.\mid I_{n}\left(C_{\Pi}+C_{\amalg}\right)+2 m_{H} l^{2} C_{\Pi}\right\rfloor_{\mp}}{2 I_{n} m_{H}} \\
\mp \frac{\sqrt{\left[I_{n}\left(C_{\Pi}+C_{\amalg}\right)+2 m_{H} l^{2} C_{\Pi}\right]^{2}-4 \cdot 2 I_{n} m_{H} l^{2} C_{\Pi} C_{\amalg}}}{2 I_{n} m_{H}} .
\end{gathered}
$$

Після розкриття виразу кругової частоти $\omega$ за допомогою формули (13) отримуємо критичні параметри кінематичних збурень 3 наступного рівняння:

$$
\begin{gathered}
\left(\frac{4 \pi^{2} v^{2}}{l_{0}^{2}}\right)_{1,2}=\frac{\left[I_{n}\left(C_{\Pi}+C_{\amalg}\right)+2 m_{H} l^{2} C_{\Pi}\right]_{\mp}}{2 I_{n} m_{H}} \\
\mp \frac{\sqrt{\left[I_{n}\left(C_{\Pi}+C_{\amalg}\right)+2 m_{H} l^{2} C_{\Pi}\right]^{2}-4 \cdot 2 I_{n} m_{H} l^{2} C_{\Pi} C_{\amalg}}}{2 I_{n} m_{H}},
\end{gathered}
$$

у тому числі розв'язуючу умову для резонансних швидкостей

$$
\begin{gathered}
v_{1,2}^{2}=\frac{\left.l_{0}^{2} \mid I_{n}\left(C_{\Pi}+C_{\mathrm{\amalg}}\right)+2 m_{H} l^{2} C_{\Pi}\right]_{\mp}}{4 \pi^{2} \cdot 2 I_{n} m_{H}} \\
\mp \frac{l_{0}^{2} \sqrt{\left[I_{n}\left(C_{\Pi}+C_{\amalg}\right)+2 m_{H} l^{2} C_{\Pi}\right]^{2}-4 \cdot 2 I_{n} m_{H} l^{2} C_{\Pi} C_{\amalg}}}{4 \pi^{2} \cdot 2 I_{n} m_{H}} .
\end{gathered}
$$

де $v_{1,2}$ - швидкості контейнеровоза, які викликають резонансні коливання у збуреному русі по першій $\varphi$ та по другій $y_{н}$ узагальнених координатах, м/с.

Збільшення навантажень на вузли пружної підвіски контейнеровоза, а разом 3 тим і на бугельну раму напівпричепа при русі по нерівностях технологічних доріг характеризуємо знову коефіцієнтом динамічності, який залежить від конструктивної особливості підвіски, параметрів кінематичних збурень, швидкості руху і визначається залежністю (22).

Розкриваємо запис амплітуди коливань $f_{g}$ з урахуванням виразів (44):

$$
f_{\partial}=\left(l A_{1}-A_{2}\right) \sin \omega t \text {. }
$$

Знаходимо максимальне значення амплітуди коливань $f_{\partial}$ з урахуванням позначення та виразів (51) та (52):

або після скорочення:

$$
f_{\partial \max }=\frac{2 C_{n} C_{u} l^{2} h_{0}-\left(2 C_{n} C_{u} l^{2}-I_{n} C_{u} \omega^{2}\right) h_{0}}{I_{n} m_{H}\left(\omega^{2}\right)^{2}-\left[I_{n}\left(C_{n}+C_{u}\right)+2 m_{H} l^{2} C_{n}\right] \omega^{2}+2 C_{n} C_{m} l^{2}}
$$

$$
f_{\partial \max }=\frac{I_{n} C_{u} \omega^{2} h_{0}}{I_{n} m_{H}\left(\omega^{2}\right)^{2}-\left[I_{n}\left(C_{n}+C_{u}\right)+2 m_{H} l^{2} C_{n}\right] \omega^{2}+2 C_{n} C_{u} l^{2}} .
$$


Визначаємо коефіцієнт динамічності по формулі (22) з урахуванням виразу (60):

$$
K_{\partial}=1+\frac{h_{0}}{f_{\partial}} \cdot \frac{I_{n} C_{u} \omega^{2}}{I_{n} m_{H}\left(\omega^{2}\right)^{2}-\left[I_{n}\left(C_{n}+C_{u}\right)+2 m_{H} l^{2} C_{n}\right] \omega^{2}+2 C_{n} C_{u} l^{2}} .
$$

Після простих перетворень у виразі (65) отримуємо наступне біквадратне рівняння відносно кругової частоти кінематичних збурень:

$$
\begin{gathered}
f_{c}\left(K_{\partial}-1\right) I_{n} m_{H}\left(\omega^{2}\right)^{2}-\left[I_{n}\left(C_{n}+C_{u}\right) f_{c}\left(K_{\partial}-1\right)+\right. \\
\left.+2 m_{\mu} l^{2} C_{n} f_{c}\left(K_{\partial}-1\right)+I_{n} C_{u} h_{0}\right] \omega^{2}+2 C_{n} C_{u} l^{2} f_{c}\left(K_{\partial}-1\right)=0 .
\end{gathered}
$$

Вводимо наступні позначення:

$$
\begin{gathered}
f_{c}\left(K_{\partial}-1\right) I_{n} m_{H}=a ; \\
I_{n}\left(C_{n}+C_{u}\right) f_{c}\left(K_{\partial}-1\right)+2 m_{H} l^{2} C_{n} f_{c}\left(K_{\partial}-1\right)+I_{n} C_{u} h_{0}=b ; \\
2 C_{n} C_{u} l^{2} f_{c}\left(K_{\partial}-1\right)=c .
\end{gathered}
$$

Тоді рівняння (66) приймає наступний вигляд:

$$
a\left(\omega^{2}\right)^{2}-b \omega^{2}+c=0 .
$$

Розв'язуємо це біквадратне рівняння:

$$
\omega_{1,2}^{2}=\frac{b \mp \sqrt{b^{2}-4 a c}}{2 a} .
$$

У виразі (71) розкриваємо кругову частоту кінематичних збурень:

$$
\frac{4 \pi^{2} v^{2}}{l_{0}^{2}}=\frac{b \mp \sqrt{b^{2}-4 a c}}{2 a},
$$

звідки отримуємо умову для швидкості переміщення контейнеровоза, при якій реалізується всякий, наперед заданий, коефіцієнт динамічності $K_{\partial}$ :

$$
v=\frac{l_{0}}{2 \pi} \sqrt{\frac{b \mp \sqrt{b^{2}-4 a c}}{2 a}},
$$

де величини $a, b, c$ обчислюються за формулами (67)—69) відповідно.

\section{Висновки та перспективи подальших досліджень}

У результаті проведеного теоретичного дослідження динаміки зчленованого контейнеровоза з бугельною рамою розроблені математичні моделі збуреного руху у поздовжній площині з урахуванням жорсткої та пружної підвісок на базі математичного апарату аналітичної механіки, у тому числі рівняння Лагранжа другого роду.

Розроблена математична модель збуреного руху у поздовжній площині обгрунтовує аналітичне визначення розрахункових навантажень на силові елементи несучої системи в залежності від типу підвісок, параметрів кінематичних збурень, режимів руху на шляху залучення коефіцієнтів динамічності. Ця модель розкриває можливості антирезонансних режимів руху, коли забезпечується квазістатичне навантаження несучої системи.

У подальших дослідженнях контейнеровозів на пневмоколісному ході з бугельною рамою слід працювати у напрямку розробки математичних моделей формування розрахункових навантажень на силові елементи несучої системи, сприйняття та передачі внутрішніх зусиль, а також науково-методичних основ проектувального та перевірочного розрахунків на міцність силових елементів бугельної несучої системи на шляху розробки та створення довершених зразків спецавтотранспорта за критерієм мінімальної металомісткості. 


\section{Список використаної літератури}

1. Грифф М.И. Автотранспортные средства с грузоподъемными устройствами для перевозки грузов в контейнерах и пакетах / М.И. Грифф, Р.А. Затван, В.Ф. Трофименко. - М.: Транспорт, 1989. - 159 с.

2. Грушников В.А. Выбор транспортных средств для контейнерной доставки строительных грузов / В.А. Грушников // Промышленный транспорт. - 1987. - №11. - С. 7.

3. Золотарев А.Ф. Контейнеровоз на базе трактора Т-150К / А.Ф. Золотарев, И.А. Тоцкий // Промышленный транспорт. - 1979. - №6. - С. 22.

4. Пашков А.К. Проектирование и перевозка тарно-штучных грузов / А.К. Пашков, Ю.Н. Поля-рин. - М.: Транспорт, 2000. -254 с.

5. Малиновский Е.Ю. Динамика самоходных машин с шарнирной рамой (колебания и устойчивость движения) / Е.Ю. Малиновский, М.М. Гайцгори. - М.: Машиностроение, 1974. $172 \mathrm{c}$.

6. Бейгул О.О. Динаміка збуреного руху зчленованого спецавтотранспортного засобу з Uподібною вантажною рамою / О.О. Бейгул, Г.Л. Лепетова // Сб. науч. тр. КГМТУ: Механика твердого тела. Механизация производственных процессов рыбного хозяйства, промышленных и аграрных предприятий. - Керь: КГМТУ, 2013. - Вып. 15. - С. 15-20.

7. Веселов Г.П. Аналитическое исследование колебаний системы тягач-прицеп / Г.П. Веселов, А.Н. Густомясов, В.И. Колмаков // Известия вузов. Машиностроение. - 1988. - №5. - С. $92-$ 97.

8. Лобас Л.Г. Динамическое поведение двухзвенного автопоезда вблизи границы области устойчивости / Л.Г. Лобас, Ю.Л. Ващенко // Прикладная математика. - 1991. - Т.27. - №12. С. 85-91.

9. Дослідження та вибір типу несучої системи автоскраповоза з U-подібною рамою / [О.О. Бейгул, М.М. Корнійчук, Г.Л. Лепетова, Д.В, Найда] // Надійність металургійного обладнання. Зб. наук. праць 3 матеріалами Міжнародної науково-технічної конференції, 28-31 жовтня 2013p. - Дніпропетровськ: IMA-прес, 2013. - С. 138-141.

10. Бейгул В.О. Математична модель збуреного руху системи «буксировщик-автосамоскид» / B.О. Бейгул, I.I, Лєєпа, Г.Л. Лепетова // Системні технології. - Дніпропетровськ: ДНВП «Системні технології», 2006. - Вип. 4(45). - С. 94-98.

11. Яблонский А.А. Курс теории колебаний / А.А. Яблонский, С.С. Корейко. - М.: Высшая школа, 1966. -255 с.

12. Бронштейн И.Н. Справочник по математике для инженеров и учащихся втузов / И.Н. Бронштейн, К.А. Семендяев. - 13-е изд., испр. - М.: Наука, 1986. - 544 с.

\section{INFLUENCE OF SUSPENSION TYPE UNDER FORMING OF DYNAMICAL LOADS TO CARRIER SYSTEM OF ARTICULATED CONTAINER TRUCK WITH BAND LOOP SUPPORTING STRUCTURE}

Beygul O.O., Grischenko D.I., Beygul V.O., Lepetova A.L.

\footnotetext{
Abstract

The metallurgical branch of industry evolves mechanization and automatization of transportal operations at technological lines for new problems of perspective models special motor-vehicle working out. The band loop load-carrying system on pneumatic wheels is optimum for container transportation of technological palletized cargo. Special motor-vehicles with such configuration are absent, therefore investigation and calculation of container motor-vehicles with band loop load-carrying system rational parameters are well timed and important.

Object of research is working-out of forming load mathematical model and sizing of articulated container truck on pneumatic wheels with band loop supporting structure.
} 
New relations is receiving for shaping of dynamical loading toward band loop frame for articulated container truck on pneumatic wheels by rigid and elastic suspensions. Methods of testing bases one's arguments upon on work out mathematical model of disturbance motion for articulated container truck at motion on technological roads of industrial plants. Kinematic disturbances are basic source of disturbances from uneven technological roads, which have been approximated by harmonical functions. Mathematical model of theoretical investigation base one's arguments upon methodology of analytical mechanics, Lagrange equation of second type. Articulated container truck has been loaded to articulated dynamical system with two degree of freedom for construction two differential equations; the second equation have right part, which describes parameters of kinematic disturbances. After decision differential equations resonance and antiresonance conditions of articulated container truck has been received. Decision of equations has been demonstrated algorithm of influence on system parameters in stage of structure working out with plan of perfect design working out for articulated container truck with band loop frame and different suspensions. Therefore this investigation has big practical meaning.

\section{References}

[1] Griff M.I., Zatvan R.A., Trofimenko V.F. Avtotransportnye sredstva s gruzopodyomnimy ustroistvamy dlia perevozky $v$ konteinerah $i$ paketah [Motor-vehicle transport means with lifting power gear for load transportation in containers and packets]. Moscow, 1989, 159 p. (in Russian).

[2] Grushnikov V.A. Vibor transportnih sredstv dlia conteinernoy dostavky stroitelnyh gruzov [Selection of transportal means for container lift of structural loads]. Industrial transport, 1987, no.11, p.7 (in Russian).

[3] Zolotaryov A.F., Totskiy I.A. Konteinerovoz na baze tractora T-150K [Container truck by base tractor T-150K]. Industrial transport, 1979, no. 6, p. 22 (in Russian).

[4] Pashkov A.K., Polyarin Y.N. Paketirovanye i perevozka tarnoshtuchnih gruzov [Piling and transportation of container loads]. Moscow, 200, 254 p. (in Russian).

[5] Malinovskiy E.Y., Gaytsgory M.M. Dinamika samohodnih mashin s sharnirnoy ramoy (Kolebaniya i ustoichivost dvizheniya) [Dynamics of automotive vechicles with hinger frame (vibrations and stability of traffic)]. Moscow, 1974, 172 p. (in Russian).

[6] Beygul O.A., Lepetova A.L. Dinamika zburenogo ruchu zchlenovanogo spetsavtotransportnogo zasobu z U-podibnoyu vantazhnoyu ramoyu [Dynamics of articulated special transport with band loop load frame motion distorbance]. Sciences works KSSTU: Mechanics of hard body, 2013, no.15, pp. 15-20 (in Ukrainian).

[7] Veselov H.P., Hustomyasov A.N., Kolmacov V.I. Analiticheskoye issledovaniye kolebaniy sistemy «tiagach-pritsep» [Analytical investigation of system «tractor-trailer» vibrations]. News of universities: Engineering, 1988, no. 5 pp. 92-97 (in Russian).

[8] Lobas L.H., Vaschenko Y.L. Dinamicheskoye povedeniye dvuhzvennogo avtopoezda vblizy granitsy oblasty ustoichivosty [Dynamical behaviour of twin-section motor-vehicle by boundary line stability]. Applied mathematic, 1991, no. 12, pp. 85-91 (in Russian).

[9] Beygul O.A., Korniychuk M.M.,Lepetova A.L., Nayda D.V. Doslidzhennia ta vibir tipu nesuchoyi sustemy avtoskrapovoza z U- podibnoyu ramoyu [Investigation and selection of loadcarrying system container truck with U-similar frame type]. Reliability of metallurgical equipment: Sciences works of International conference 28-31.10.2013. pp. 138-141 (in Ukrainian).

[10] Beygul V.O., Leepa I.I., Lepetova A.L. Matematichna model zburenogo ruhu sustemy «buksirovschyk-avtosamockyd» [Mathematical model of disturbance motion for system «motor tugmining rear dumper»]. Sciences works «system technology», 2006, no. 4(45), pp. 94-98 (in Ukrainian).

[11] Yablonskiy A.A., Noreico S.S. Curs teoriy kolebaniy [Science of vibrations theory]. Moscow, 1966, 255 p. (in Russian).

[12] Bronshtein I.N., Semendiaev K.A. Spravochnik po matematike dlia inzhenerov i uchaschihsia vtuzov [Mathematical reference book for engineers and students of technical university]. Moscow, 1986, 544 p. (in Russian). 